\title{
El cuerpo y el lienzo. Las performances de las protestas feministas y laborales en Santiago
}

The body and the canvas. Performances of feminist and labor protests in Santiago

\section{Nicolás Orellana}

Universidad de Chile, Santiago, Chile

nicolasorellanadiap.uchile.cl

https://orcid.org/0000-0002-9002-4502

\author{
Catalina Chamorro \\ Universidad Católica del Maule, Talca, Chile \\ Universidad Academia de Humanismo Cristiano, \\ Santiago, Chile \\ cchamorroducm.cl \\ https://orcid.org/0000-0002-2518-9060
}

\section{Resumen}

El análisis de las movilizaciones sociales en Chile ha girado principalmente en torno a las racionalidades, estrategias y objetivos de las protestas. Aunque emergentes, los estudios sobre performatividades y cuerpos de protesta son aún marginales. Este artículo se centra en ello, mediante un estudio de la marcha feminista del $8 \mathrm{M}$ y la del primero de mayo clasista y combativo de 2019 en Santiago, Chile. A través de un enfoque etnográfico, nos centramos en cuerpos, estéticas y materialidades desplegadas, para observar las performances de las movilizaciones, dando cuenta de la complejidad de los procesos comunicativos que se ponen en juego en estas instancias. Argumentamos que, mientras en las manifestaciones de carácter experiencial y descentrada, el discurso se expresa heterogéneamente en los cuerpos, articulando lo personal y lo políti$\mathrm{co}$, en las manifestaciones de carácter colectivista y centralizada, éste se expresa mediante lienzos soportados por corporalidades homogéneas, demostrando la emergencia de lo colectivo por sobre las experiencias personales.

Palabras clave: movilización social, performance, cuerpo, acción contestataria, culturas populares.

\section{Abstract}

The analysis of social mobilizations in Chile has revolved mainly around the rationale, strategies, and objectives of the protests. Although emerging, performativity and body are rather marginal subjects in protest studies. This article focuses on these elements by closely discussing two massive protests: the feminist Women's March (known as 8M) and the classist and combative Labor Day on May $1^{\text {st }}$, both demonstrations that take place in 2019 in Santiago, Chile. Based upon an ethnographic approach, we focus on bodies, aesthetics, and materialities performed in such events. By doing so, complex communicative processes emerge from these public demonstrations. In manifestations of an experiential and off-centered nature, the discourse articulates both the personal and political dimensions and is heterogeneously embodied in actual bodies, proving that personal is political. On the other hand, in manifestations of a collective and centralized nature, the discourse is expressed through canvases embodied in homogeneous corporality. This shows the emergence of the collective over personal experiences.

Keywords: social mobilization, performance, body, contentious action, popular cultures. 


\section{Introducción}

Los abordajes tradicionales de la acción colectiva y los movimientos sociales han permitido dar cuenta de elementos relevantes para comprender algunas de las dimensiones de la movilización social. Sin embargo, éstos se tornan insuficientes para comprender la emergencia que han adquirido los cuerpos ${ }^{1}$ y las performances como acciones comunicativas centrales de las protestas contemporáneas. La relevancia de develar el lugar del cuerpo y las performances de la protesta implica preguntarse sobre los modos en que los activismos se despliegan en el espacio público en contextos de movilización. Este artículo describe y analiza, desde un enfoque etnográfico, las dinámicas performativas de dos manifestaciones contestatarias distintas; sitúa el cuerpo y la performance al centro de la observación y el análisis y, con ello, indaga en los modos de comunicación simbólica que cuerpos y performances transmiten.

En Chile, las manifestaciones durante lo que va del siglo XXI han sido persistentes IOrellana, 2020). Luego de un proceso de desmovilización durante la década de 1990 (Aguilera, 2012; Álvarez, 2014; Osorio \& Gaudichaud, 2018), los ciclos de movilización que han emergido en la escena pública han sido continuos. Trabajadores, pueblo Mapuche, estudiantes, pobladores, se han manifestado sostenidamente. Sin embargo, en la última década han emergido actores, así como también demandas, que antes se encontraban subordinadas y dispersas. Entre estos nuevos actores y demandas destacan los movimientos medioambientales, las disidencias sexuales y los movimientos feministas, que han irrumpido con particular fuerza en los últimos años en la escena pública y política, tanto en Chile como en el mundo (Bolados \& Sánchez, 2017; Garrido \& Barrientos, 2018, González, 2019). Con ello, en las reuniones contestatarias, entendidas como "asambleas públicas visibles en las que intereses en conflicto están claramente en juego" (Tilly, 1978, p. 8), han aparecido y cobrado relevancia no sólo actores/ actrices y demandas, sino también nuevas escenificaciones de protesta que expresan, de modos diversos, contenidos contestatarios, desplegando cuerpos, estéticas y materialidades de modos diferentes a los tradicionales.
Este artículo describe y analiza las dinámicas de contestación de dos tipos de manifestaciones contemporáneas, la Marcha Feminista del $8 \mathrm{M}$ y la marcha del Primero de Mayo Clasista y Combativo del año 2019 en Santiago de Chile, para observar y comparar cómo se comunican performativamente los contenidos contestatarios. ¿Qué elementos configuran las performances de estas acciones contestatarias? ¿Es posible identificar, en los despliegues performativos, formas distintas de expresar culturas de resistencia, subversión y/o reivindicación? Nuestra hipótesis sugiere que la diferencia entre ambas manifestaciones radica en el locus del cuerpo como medio de la expresividad contestataria. Mientras que en la marcha del $1^{\circ} \mathrm{de}$ mayo, el cuerpo se escinde de la demanda al utilizarlo como soporte para desplegar otras formas de comunicación, en la marcha feminista del $8 \mathrm{M}$ el cuerpo es medio de expresión central de su acción transformadora.

Argumentamos entonces que, en una marcha de carácter colectivista y centralizada como la del primero de mayo, el contenido se comunica principalmente a través de la palabra llogo centrismol. El lienzo ocupa el centro de la escena y, en su homogeneidad, los cuerpos se funden en una producción y comunicación de sentido liderada por esta materialidad. Mientras que, en una marcha experiencial, descentrada y situada, como la marcha feminista del $8 \mathrm{M}$, los cuerpos mismos se transforman en contenido contestatario y se tornan expresividad comunicativa a través de su acción performativa. Mientras en las primeras la performance se objetiviza en el lienzo, en las segundas ella se corporiza, expresando no sólo mensajes múltiples y heterogéneos, sino también formas diferentes de oponerse a la cultura dominante, constituyendo culturas populares (GarcíaCanclini, 1989) o de resistencia.

Observar, describir y comparar las performances de protesta, poniendo el cuerpo al centro del análisis es un tema emergente en las ciencias sociales y las humanidades. Los diversos modos de comunicar activismo y compromiso sociopolítico son cuestiones que hoy adquieren preponderancia en momentos de procesos de cambio social y político significativo, en particular desde la revuelta del 18 de octubre de 2019. Comprender la multiplicidad de estas expresiones requiere de modos de acercamiento directo e intenso, para dar cuenta del lu- 
gar del cuerpo en las performances y dinámicas de protesta. Un abordaje de tipo etnográfico es el que mejor puede visibilizar estas dimensiones de la protesta. Este se basa en una observación densa, en una reflexividad dialógica y relacional y en un compromiso intersubjetivo para observar, describir, analizar e interpretar las estructuras de significación de las prácticas sociales y culturales (Restrepo, 2018; Velasco \& Díaz de Rada, 2006; Guber, 2001; Clifford, 2003 [1988]; Geertz, 2003).

En lo que sigue, abordamos la figura de los movimientos sociales, situándonos desde una perspectiva de activismos cotidianos para observar, describir y analizar las performances de la protesta. Luego, describimos nuestro modo de acercamiento a la protesta, basado en un enfoque etnográfico colectivo. Seguimos con el relato de dos marchas significativas para nuestro análisis. La marcha feminista del $8 \mathrm{M}$ y la del $1{ }^{\circ}$ de mayo clasista y combativo, ambas de 2019, centrándonos en cuerpos, estéticas y materialidades, para analizar y comparar ambas desde lo performativo. Concluimos con el alcance y las posibilidades que un enfoque etnográfico de performances de las protestas puede entregar para una comprensión multidimensional de la movilización social.

\section{Marco teórico}

Los estudios sobre la acción colectiva y los movimientos sociales han tenido dos grandes perspectivas de reflexión y de análisis. Por un lado, la teoría de los nuevos movimientos sociales (NMS) que analiza las conductas colectivas organizadas que luchan por la dirección de la historicidad y que devela lógicas de acción y conflictos entre actores sociales (Touraine, 1978). Por otro, la teoría de movilización de recursos (TMR) concibe a los movimientos sociales como preferencias de una población hacia el cambio de la estructura o del modo en que se distribuyen las recompensas (McCarthy $\&$ Zald, 1977). Con sus propias derivaciones, los aportes de la perspectiva identitaria y estratégica (Tarrés, 1992) para el análisis de los movimientos sociales son innegables, y han sido utilizados en América Latina y Chile, de modo recurrente y reciente (Escobar \& Álvarez, 1992; Salinas, 2016; Salazar, 2012).
Sin embargo, ambas perspectivas, surgidas en períodos previos a las grandes reestructuraciones neoliberales y basándose en lógicas de militantes -heroicos o retribuidos- (Pudal, 2011; Aiziczon, 2018), omiten aspectos que hoy resultan fundamentales para una observación más compleja de lo que "hacen" las y los activistas cuando protestan y resultan insuficientes para comprender los fenómenos contestatarios contemporáneos. Entre las dimensiones que hoy aparecen como relevantes para comprender el activismo, el cuerpo, las performances, los rituales y las emociones emergen como campos prometedores para estudiar movilizaciones, aportando modos de comprensión de los compromisos contestatarios "a través de lo que ellos hacen, o más bien a través de cómo lo hacen, que (...) anuncian a la sociedad que algo 'otro' es posible" (Melucci, 1985, p. 812).

En este artículo, más que una lógica de militancias, nos centramos en una perspectiva de activismos, que no separan lo personal de lo político (Portwood-Stacer, 2013; Hanish, 2016 [1969]), para proponer una observación y comprensión de las dinámicas de protesta basada en performances. Esta perspectiva, inspirada en diversas fuentes tanto teóricas como empíricas (Fernandes-Jesus, Lima \& Sabucedo, 2018; De Moor, 2017; Cherry, 2014; Sotirakopoulos, 2016; Yates, 2014; Haenfler, Johnson \& Jones, 2012), permite comprender la multidimensionalidad de los activismos, colocando al centro las vidas enteras, en lugar de separar el compromiso sociopolítico de las vidas cotidianas.

Una perspectiva basada en este enfoque da cuenta con mayor precisión de activismos como las disidencias sexuales, los feminismos, los medioambientalismos u otros, pero también permite comprender de un modo nuevo las militancias tradicionales. En el primer caso, porque son las vidas enteras las que se ven implicadas en dichos compromisos, mientras que en el segundo permite ampliar la perspectiva hacia aspectos no considerados en el análisis tradicional. En este sentido, analizamos la acción colectiva en ambos casos en términos culturales más que en términos políticoinstitucionales, ya que en lugar de ver la militancia "como un preámbulo para la participación política" (Nash, 2001, p. 86), considera el activismo como un fin en sí mismo, que impregna la vida entera, y que privilegia una coherencia entre prácticas cotidianas 
y acción colectiva, poniendo de manifiesto los compromisos de transformación política en diversos espacio-tiempos sociales. En tanto formas de interacción conflictiva con los sectores hegemónicos (García-Canclini, 1989), ambos casos constituyen culturas de resistencia en que los sujetos populares emergen como hablantes, como sujetos/as capaces de acción y lenguaje (Berger \& Carrizo, 2016; Hall \& Jefferson, 2003), pero donde cuerpos y performances contestatarias ocupan lugares distintos en el escenario de manifestación. Junto con observar la dinámica de producción comunicativa, esto permite "ir más allá del dualismo mente/ cuerpo que subyace a tantos relatos de la cultura del movimiento social" (Juris, 2015, p.85).

En este sentido, la acción contestataria constituye una práctica simbólica y cultural encarnada (hecha cuerpol por los activistas contestatarios, que se manifiesta tanto en los espacios de visibilidad (manifestaciones públicas), como en los de latencia (vida cotidiana) (Véron, 2016). Es decir, son formas de vida constitutivas de identidades que promueven y fomentan el cambio social (Haenfler, Johnson \& Jones, 2012; Chatterton \& Pickerill, 2010; Boudreau, Boucher \& Ligouri, 2009).

En este marco, el análisis de performances es relevante pues permite captar las diferencias entre ambos tipos de manifestación bajo un mismo prisma. La performance es un término polisémico, aplicable a diversos campos semánticos y disciplinas que abordan la complejidad de las situaciones representacionales (Taylor, 2011; Prieto, 2002). La entendemos como "el proceso mediante el cual los actores, individualmente o en conjunto, exhiben para otros el significado de su situación social" (Alexander, 2005, p. 19) a través de la escenificación reiterativa de acciones con sentido simbólico (Taylor \& Fuentes, 2011; Fischer-Lichte, 2011; Schechner, 2013 [2002]). Desde esta perspectiva, la performance es un acto comunicativo constituido por actores que emiten mensajes, verbales y no verbales, a una audiencia receptora de los significados emitidos en la práctica performativa (Juris, 2015). Además, tiene un sentido cultural, en tanto es "un lente epistémico para analizar las prácticas culturales en las que el cuerpo resulta el principal medio de transmisión de conocimiento, memoria social y sentido de identidad" (Taylor \& Fuentes, 2011, p. 403).
Consideramos entonces que "los significados e identidades culturales alternativos se producen en gran medida a través de la performance cultural encarnada" (Juris, 2015, p. 84-85) y, por lo tanto, observamos la acción contestataria a partir de este acto comunicativo simbólico que ejercen los activistas, de forma reiterativa como expresión cultural de resistencia, subversión y/o reivindicación. Como portador de signos encarnados, el cuerpo activista se transforma en un espacio de acción política, instrumentalizado, que produce y difunde ideas, significados e identidades (Juris, 2015; Fischer-Lichte, 2011). En este sentido, la dimensión simbólica de la performance se encarna en quienes la ejecutan, posicionando al cuerpo como elemento central del análisis. Activismos, cuerpo y performances se sitúan, de este modo, como los ejes articuladores desde los cuales damos cuenta de los hallazgos de este estudio, y analizamos las manifestaciones arriba mencionadas.

\section{Marco metodológico}

Para describir e interpretar los modos en que diversas manifestaciones contestatarias despliegan performances distintivas, desarrollamos un enfoque etnográfico; vale decir, una observación densa de manifestaciones contestatarias. La etnografía tiene por objetivo lograr el acceso a los significados que los sujetos le dan a sus prácticas sociales, a través de una observación próxima, sensible, reflexiva y relacional, basada en un compromiso inter-subjetivo que implica la participación en la realidad social estudiada (Restrepo, 2018; Guber, 2001; Velasco \& Díaz de Rada, 2006; Geertz, 2003 [1973]). La etnografía, además, permite observar la performance y, como dice Fischer-Lichte, "concederle al cuerpo una posición de prevalencia paradigmática (...), en lugar de subsumirlo al paradigma textual" (2011, p. 184).

La evidencia empírica de las manifestaciones, entendidas como una "cristalización social efímera e informal” (Delgado, 2004, p. 127), caracterizadas por su multiplicidad, su intensidad y su fugacidad, la recolectamos mediante etnografías colectivas (Jirón \& Imilan, 2016). Específicamente, trabajamos como un equipo etnográfico, compuesto por 
cinco personas de diversas disciplinas lantropología, sociología, diseño, artes escénicas), que permitió develar múltiples matices de las prácticas contestatarias, sus estéticas, materialidades y expresividades corporizadas, con la finalidad de capturar sus estructuras de significación (Geertz, 2003 [1973]).

Nuestra estrategia fue participar de estas manifestaciones, poniendo atención a los elementos significativos para nuestra investigación, cubriendo de este modo diversas facetas y dimensiones ${ }^{2}$. Entre las manifestaciones en que participamos, observamos y describimos durante el año 2019, se encuentran la marcha feminista del $8 \mathrm{M}$, del primero de mayo clasista y combativo, la marcha del orgullo (22 de junio), la marcha del "11" (8 de septiembre), la marcha por el medio ambiente (27 de septiembre) y la marcha del día de la resistencia indígena (12 de octubre) en Santiago, que constituye la ciudad más poblada del país y donde estos fenómenos se pueden observar con mayor intensidad. Luego, cada integrante elaboró un relato etnográfico, acompañado por material visual, que daba cuenta de su experiencia de participación, describiendo elementos significativos en función de una matriz de observación, cuyos indicadores para identificar y describir performatividades fueron: el despliegue de actores, las estéticas, las materialidades y los modos en que éstas se expresan. Estas dimensiones resultaron las que dieron mejor cuenta del locus del cuerpo en la manifestación social.

Con la veintena de relatos recopilados de manifestaciones, sistematizamos la información producida y realizamos un análisis comparativo, en el cual pudimos discernir performances distintivas y modos de expresión de compromisos sociopolíticos de las/os activistas de estas manifestaciones. Con esta información, nos concentramos en la marcha feminista del $8 \mathrm{M}$ y la marcha del primero de mayo clasista y combativo, pues dan mejor cuenta de los elementos significativos que aquí exponemos. La primera, como una marcha en la que son las múltiples dimensiones de las vidas enteras de mujeres las que se ponen en juego, mientras que la segunda, es una sola dimensión, el trabajo, la que se presenta como demanda principal, subordinando otras demandas a ella.

A continuación, presentamos los relatos etnográficos de ambas marchas, con la finalidad de analizar y comparar sus performatividades características que comunican simbólicamente contenido contestatario, analizando el lugar y relevancia del cuerpo en cada una de ellas.

\section{Resultados}

\subsection{Marcha feminista 8M. El cuerpo como medio de transmisión simbólica del contenido contestatario}

Como todos, el 8M del 2019 era un típico día de principios de marzo cuando aún se siente el verano. No sólo por el sol que entibiaba, sino también porque el ánimo de la ciudad tenía esa característica energía del reencuentro después de los meses de vacaciones. Así también fue nuestra llegada como equipo etnográfico a la marcha donde, por distintos accesos a la ahora llamada Plaza de la Dignidad, cada una de nosotras tendría su propio encuentro para avanzar junto a alguna amiga-compañera. En concordancia con lo que señala en su página web la coordinadora convocante, se puede entonces ver éste como un espacio de participación de múltiples y diversas organizaciones sociales o políticas, pero también de múltiples individualidades.

Y así fue la marcha ese día, además de sorprendentemente multitudinaria. "Era como estar en un recital", describe una de las integrantes del equipo etnográfico, "pero uno con coches, guaguas, niñas/ os y adultas mayores". Esa diversidad de colectivos, individualidades, edades e integrantes daban paso a una diversidad de colores y formas de expresión que, a diferencia de otras marchas, llegaban a instalarse en el lugar de la convocatoria e, incluso, a armarse y articularse allí mismo. El acceso a través del Parque Bustamante es donde esto resultaba más evidente. En la medida que uno se acercaba a la estación de metro Baquedano, se podían observar grupos de mujeres realizando preparativos para desplegar en la marcha. Se veían grupos pintando carteles en el piso de los alrededores del Café Literario, otros reunidos en círculos que ensayaban cantos, instrumentos o alguna danza alrededor de la pileta. Cerca del monumento a Baquedano y frente al teatro de la Universidad de Chile, también se observaban grupos que realiza- 


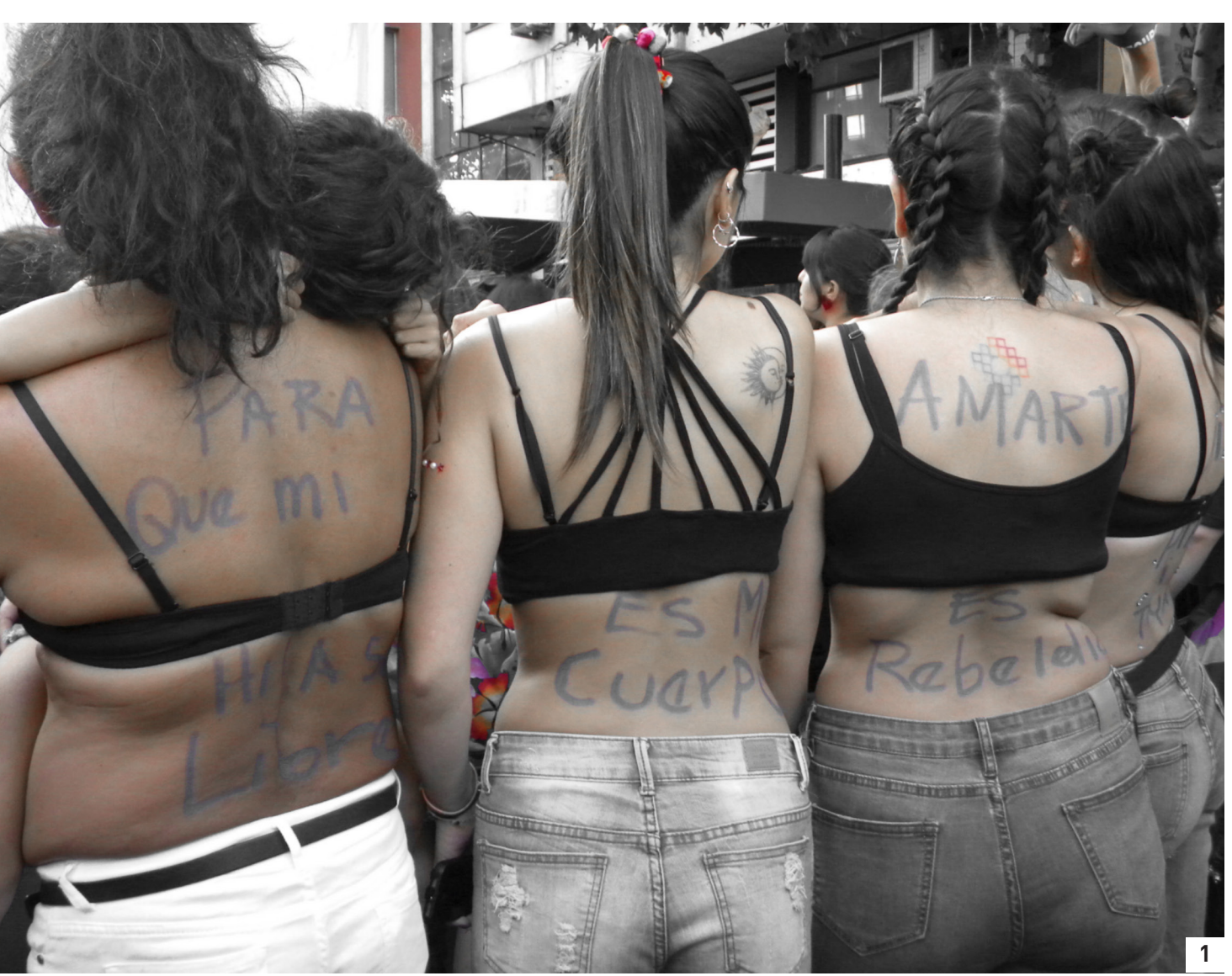

Fotografía 1. Marcha 8M.

Fuente: Archivo propio.

ban intervenciones, utilizando sus cuerpos y otros elementos simbólicos como flores, fotos o velas. También se podían ver agrupaciones que preparaban acciones rituales como las Sahumadoras ${ }^{3}$ que, con sus copaleras encendidas, se iban posicionando concentradas para marchar. Todo esto formando un escenario caracterizado por la aparición de una enorme paleta de colores, así como formas de vestir, desvestir y hacer presencia de los cuerpos. El único código compartido era el pañuelo verde -en apoyo a la legalización del aborto o morado en representación del movimiento feminista-, y que las mujeres asistentes vestíamos casi uniformemente.

A medida que el tiempo pasaba y la marcha demoraba más que otros años en comenzar, nos preguntamos: ¿dónde empieza esto? Curiosamente, en esta ocasión, esa no resultó una pregunta fácil de responder y nos detuvimos, entonces, a pensar que ello nos daba pistas de una de las características de esta marcha. Si bien se reconoce a la Coordinadora $8 \mathrm{M}$ como la principal organización convocante y pudimos ver que ésta se encontraba cerca del monu- mento a Baquedano, no encabezaba la marcha. De hecho, la marcha parecía no tener inicio, sino que era un inmenso mar humano al que se sumaban y sumaban activistas en distintos puntos del recorrido. En ese momento reparamos en que esta manifestación no se estructuraba como una gran columna en torno a la figura principal de la organización convocante, sino que iba tomando forma a partir de la espontánea manera en que las personas se integraban a ella desde distintos accesos. Tampoco se vislumbraba fácilmente a las fuerzas policiales, ya que no demarcaban el espacio de la marcha, sino que fueron apareciendo en puntos claves del recorrido hasta la estación de metro Los Héroes.

A lo largo de la movilización, no se ve una presencia mayoritaria del formato tradicional de lienzos colectivos y banderas de las organizaciones, sino que primaban los carteles pequeños, escritos a mano con plumones, témperas u otros materiales en soportes sencillos como cartones, cartulinas y hojas de papel. Además, observamos el uso de muchos objetos que adquirían un carácter simbólico, como 
las velas, fotografías, las flores, pero también otros que servían para vestir los cuerpos, enfatizándolos como presencia activa. El pañuelo como el más significativo, pero también máscaras, poleras, tocados de pelo y disfraces o vestuarios especiales, como trajes de baile o vestimentas tradicionales asociadas a algún ritual, que acompañaban los cuerpos desplegados en el espacio.

Junto a estos elementos, pero también por sí mismos, estos cuerpos, vestidos, desnudos, rayados, pintados, dispuestos en una posición específica o en movimiento, en silencio, cantando, gritando o diciendo, fueron apareciendo como el principal sostén de los mensajes de la movilización. Los mensajes inscritos en estos cuerpos iban también demostrando el poder de expresar a través de distintos lenguajes lo que se quería decir. "Para que mi hija sea libre", se leía escrito en la espalda de una madre que cargaba a su hija; "mi cuerpo es mi decisión", en el torso desnudo de una mujer; "aborto libre, seguro y gratuito", en el abdomen de una mujer embarazada; y caras o labios pintados con los colores de la causa, que transmitían no sólo con palabras aquello por lo que se estaba protestando.

También se nota una variedad enorme de discursos desplegados en los cuerpos y en el espacio. Estos discursos, heterogéneos e incluso contradictorios, no disputaban ninguna hegemonía en la manifestación, puesto que se trataba de diversas necesidades, problemáticas, derechos y definiciones de lo que es ser mujer, que aparecían de las más variadas formas. "NO es NO... ¿qué parte no entendiste? ¿la $\mathrm{N}$ o la 0 ?", se escucha en los gritos. "No soy un perro, no me silbes" o "Soy la voz de las que ya no están", se lee en los carteles. "Alerta, alerta, alerta machista... que todo el territorio se vuelva feminista", se escucha en los cantos. Y así múltiples formas aparecen para decir que se está a favor del aborto, en contra del abuso sexual, visibilizando los casos de femicidio, luchando por las desigualdades de género, por el avance del feminismo, la liberación de los cuerpos, decisiones y territorios. Son diversos los mensajes que coexisten, se mezclan, se expresan y dan vida a esta manifestación. No hay tantas consignas específicas o acompañadas del nombre de organizaciones, ni tampoco una estructura de marcha clara. Pero, sobre todo, no hay tantas palabras como cuerpos. Cuerpos que, desplegados en el espacio, actúan como medio de la comunicación de estas mujeres en movimiento.

\subsection{Marcha del primero de mayo clasista y combativo. El lienzo como soporte comunicativo central}

El miércoles primero de mayo del 2019 estaba soleado, aunque un poco frío. Como equipo etnográfico llegamos desde distintos sitios al lugar de la convocatoria, en avenida Brasil con la Alameda, a las 11:00. Quienes llegaron desde el Metro Los Héroes, al poniente del lugar de concentración, pudieron dar cuenta de la cantidad de fuerzas policiales que se encontraban delimitando la retaguardia. Quienes llegamos caminando desde el poniente, advertimos la soledad de la avenida más importante de la capital sin vehículos. Fuerzas policiales también demarcaban este lado, aunque en menor número.

En el lugar del acto, observamos un despliegue de cuerpos, estéticas y materialidades que se repite en otras manifestaciones del mismo tipo. Quienes se encontraban en las primeras filas de la manifestación eran, por lo general, personas adultas, que pertenecían a alguna organización sindical, política o social. En algunos casos, las/os militantes iban con sus familias, observándose hijas e hijos de diversas edades que acompañaban. Estas personas, si bien no necesariamente se conocen entre sí, compartían una especie de código de vestimenta, donde abundaban los pantalones rectos de mezclilla, zapatillas o bototos, chaquetas, chalecos y carteras, predominando colores y tonos de azules, blancos y rojos. Una semi-formalidad impregnaba el ambiente, dotando al espacio social de una suerte de homogeneidad, basada posiblemente menos en un aspecto ritual que en un estilo de vestimenta asociada al mundo del trabajo.

Hacia el centro de la manifestación, predominaban jóvenes. Ellas y ellos vestían principalmente de negro, combinado con colores más fuertes que en la vanguardia. Si allí el código de vestimenta era semi-formal, aquí el código era mucho más informal. Combinaciones de zapatillas deportivas, shorts o leggins, cortavientos y bananos predominaban por esta zona, dotando a los cuerpos de un aspecto más diverso y desenfadado. A veces esta estética se complementaba con ornamentos vistosos, como una activista de una organización anarco-vegana que usaba un pasamontañas negro, que tenía cosidas unas orejas y nariz de chancho. 
En la retaguardia de la concentración, se observaba una variedad de grupos, entre barras bravas, organizaciones populares de vivienda, entre otras, $y$, entre medio, grupos encapuchados, cuya estética típica Ipolera como capucha, mochila tapada y cubiertos de ropa cómoda de pies a cabezal se repite. Observamos que, al interior de estos cuatro grupos, los cuerpos tienden a hacerse homogéneos en sus estéticas y sus conformaciones socioetarias.

Antes de su inicio, esperando sumar más gente, encabezando la marcha, se encontraban los lienzos de las organizaciones convocantes. En primera fila, se veía el lienzo de la Central Clasista de Trabajadoras y Trabajadores (CCTT). El lienzo, de plástico grueso rojo y con letras blancas mayúsculas, decía “¡Viva la clase trabajadora!”, y al costado derecho el nombre de la organización. El lienzo estaba en el piso, transversal a la calzada y, tras él, también en el piso, se observaban unas banderas desplegadas (abiertas) y ordenadas en filas, algunas blancas, otras rojas, otras negras, con mensajes impresos en ellas. Hacia los costados y más atrás, se observaban también otros lienzos y banderas en el piso de otras organizaciones. Salvo algunas personas que parecían estar custodiando, era imposible distinguir dónde se encontraban las personas pertenecientes a la agrupación, aunque el espacio estaba reservado para ellas. Aún no había colectivos, sino sólo algunas personas o grupos pequeños resguardando o deambulando entre estos lienzos y banderas, que parecían esperar el inicio de la marcha.

Tras estas primeras filas, comienzan a aparecer personas y se empiezan a distinguir distintas agrupaciones. Esta vez, son colectivos, organizaciones sociales o políticas, reunidas levantando sus lienzos, banderas o pancartas. A diferencia de lo que sucede en las primeras filas, las personas portaban los objetos, haciéndose cargo directamente de los mismos. No se veían lienzos, banderas o pancartas en el piso.

La aglomeración se comenzaba a comprimir. Se distinguen las agrupaciones por medio de esos lienzos y banderas alzados, sostenidos por las personas pertenecientes a ellas. Mayoritariamente rojos y negros, con letras blancas, rojas, negras

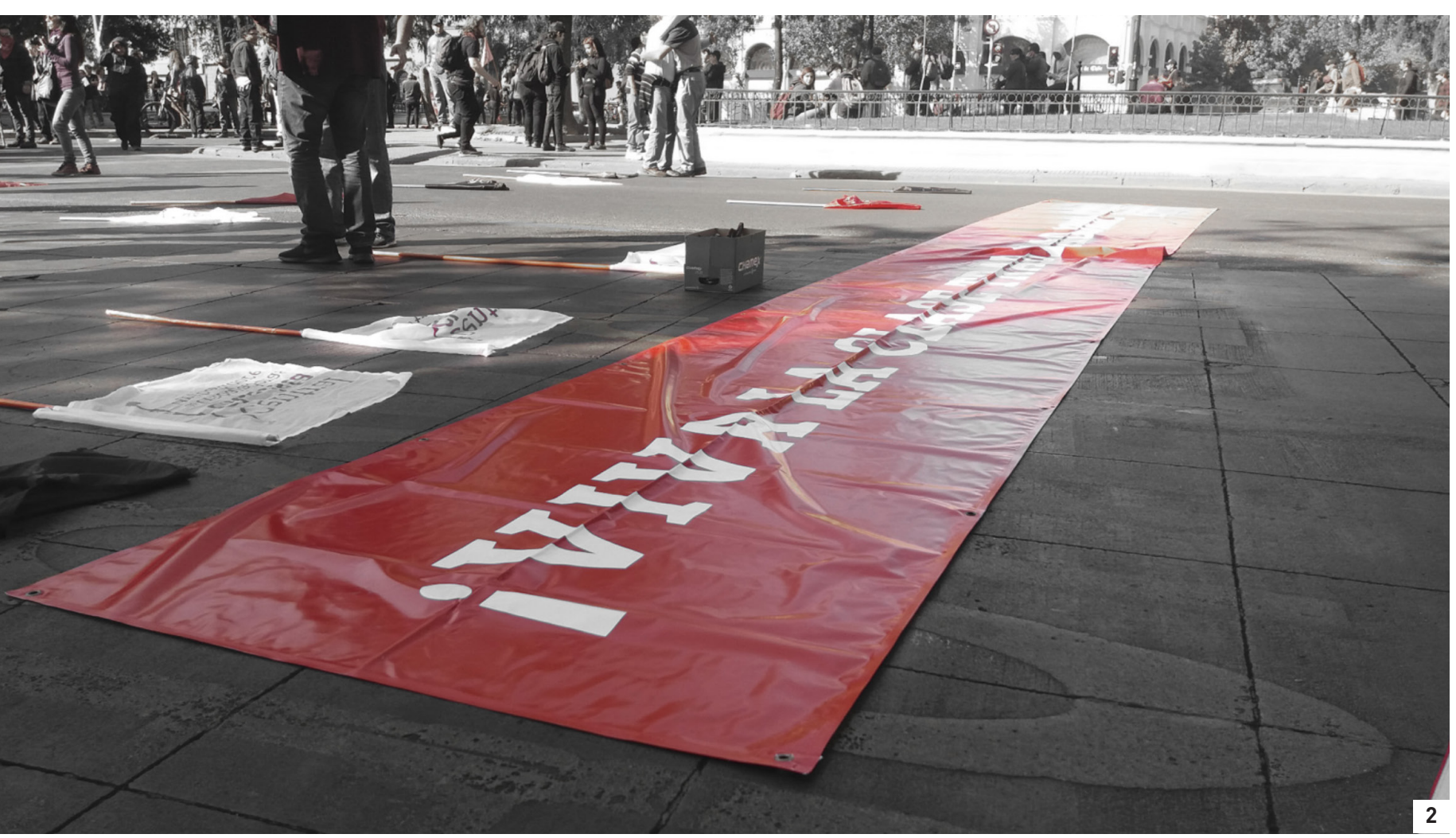

Fotografía 2: Marcha $1^{\circ}$ de Mayo de 2019. Fuente: Archivo propio. 
o azules, éstos identificaban a las personas que los portaban con un determinado colectivo u organización. El lienzo generalmente lleva escrita una consigna y, a un costado del mismo, se identifica el nombre de la organización y su sigla, aunque hay algunos que sólo incluyen la sigla de la misma. En algunos casos, el lienzo está acompañado o decorado con un dibujo que expresa la demanda. Un caso ilustrativo era una bandera chilena gigante desplegada a todo lo ancho de la calzada, de la Agrupación Nacional de Deudores Habitacionales (ANDHA), que, en lugar de la estrella, tiene dibujada una casa, símbolo de sus demandas habitacionales. Las pancartas y banderas siguen una lógica similar, aunque en las pancartas, por su tamaño, se pueden observar más dibujos y siglas que demandas extensas.

En el trayecto de la marcha por la Alameda, desde avenida Brasil hasta Estación Central, la dinámica de manifestación sigue la misma lógica de las manifestaciones de este tipo. Las y los militantes de sindicatos, colectivos, organizaciones sociales, políticas u otras, se despliegan tras el lienzo, sostenido por dos o más personas, en función de su tamaño. Cuando es un lienzo alto, lo llevan sobre las cabezas con tubos de PVC. Cuando es un lienzo a la altura del pecho, lo toman con sus manos. Las y los militantes que no transportan lienzos, caminan tras él, agrupados, llevando en muchos casos banderas o pancartas alusivas a la agrupación y a sus demandas. Otros hacen sonar estruendosamente pitos o tambores, expresando sus demandas a través del ruido, que acompaña el coro de consignas dirigidas por un vocero/a con megáfono. Cada organización opera como un conjunto relativamente homogéneo, que se organiza en torno a lienzos, banderas y pancartas, tras las que se encuentran los cuerpos y las estéticas de las/os activistas. Las estéticas y los cuerpos difieren más en función del origen socio-etario que político, que se condice con la estética y la posición de la organización en el conjunto de la manifestación.

La dinámica de esta manifestación es un despliegue de performances, donde cuerpos, estéticas y materialidades se escenifican, donde el lienzo ocupa un lugar preponderante y los cuerpos, presentes y desplegados, se tornan más soportes de dichas materialidades, que comunicantes directos de contenido contestatario.

\section{Análisis y conclusiones}

Las performances forman parte de toda protesta. Estas son comunicaciones verbales y no verbales que usan artefactos y cuerpos como medios de transmitir el significado de su situación social, inscribiendo allí identidades culturales (Taylor \& Fuentes, 2011; Juris, 2015) y, en el caso de esta investigación, compromiso contestatario. Más allá del contenido específico transmitido, nos interesamos por los modos en que estos compromisos son comunicados, para develar, a través del hacer, los anuncios de un mundo nuevo posible (Melucci, 1985).

En los casos analizados, la marcha feminista del $8 \mathrm{M}$ y del primero de mayo clasista y combativo, ambos del 2019, observamos similitudes en los modos generales de manifestarse. En ambos casos, se trata de expresiones públicas, masivas y visibles, que expresan demandas a través de una presencia y ocupación en el espacio público. Sin embargo, existen diferencias sensibles, tanto por las demandas expresadas, como por los modos en que ellas se expresan. La perspectiva de performance ayuda a dar cuenta de la relevancia específica que adquieren las materialidades y los cuerpos en estas protestas, lo que nos permite hablar de distintos modos de encarnar y manifestar demandas.

La protesta del $8 \mathrm{M}$ se configura como un espacio de participación múltiple y descentrada. Si bien se observa la presencia de organizaciones, éstas no ejercen un rol articulador de las presencias individuales. Es decir, las demandas y los modos de protestar no subordinan las expresiones individuales a una única forma colectiva, sino que éstas se expresan en diversas configuraciones que evidencian el despliegue de lo personal como político. En este sentido, la performance desplegada se caracteriza por ser heterogénea, permitiendo no sólo la emergencia de mensajes diferentes, sino incluso contradictorios, pero que no disputan la representación hegemónica de la manifestación.

En esta puesta en escena, los cuerpos son el principal medio de transmisión simbólica del contenido contestatario. No sólo al ser utilizados para inscribir los mensajes en frases escritas en espaldas, estómagos o caras, sino de las más diversas formas. A través de cantos, bailes, intervenciones, rituales 
y caminares, los cuerpos estáticos o en movimiento, vestidos o desvestidos, pintados o rayados, encarnan y expresan los heterogéneos mensajes que constituyen esta acción. Así, las múltiples demandas de esta manifestación se viven en los propios cuerpos y se expresan también de forma experiencial con la presencia del yo que se despliega en el espacio público.

La manifestación del primero de mayo clasista y combativo, por otro lado, tiene un carácter colectivo y centralizado, pues se despliega desde una orgánica más tradicional en comparación a la primera. Es decir, las demandas y los modos de protestar se centran casi exclusivamente en formas colectivas basadas en la organización (sindical, política u otral más que en las expresiones personales de sus participantes. Esta lógica hace que las múltiples dimensiones, intereses e individualidades de quienes participan de ellas queden sujetas a lo colectivo. De ahí la predominancia de materialidades como lienzos, banderas y pancartas soportados por cuerpos vestidos y dispuestos en el espacio de formas homogeneizantes que expresan un discurso enfocado en demandas de tipo estructural, clasista y universal.

En esta manifestación, así como en otras del mismo tipo (fundamentalmente la del "11"), antes de la procesión, es el lienzo en el suelo, más que el cuerpo, el que otorga una especie de derecho a la presencia. Asimismo, durante ésta, es el lienzo erguido, sobre las cabezas o a la altura del pecho, el que marca la presencia de la organización. En este sentido, la presencia colectiva está marcada por una performance centrada en la materialidad del lienzo, mientras que la homogeneidad de los cuerpos, las estéticas, los modos de hablar, de caminar, de ornamentarse, giran en torno a esa materialidad que marca esta presencia colectiva y organizada. Aquí lo personal queda sujeto a lo colectivo, y lo político está expresado performativamente en términos de un nosotros, centrado en el lienzo que enuncia logocéntricamente la demanda. Las individualidades, que forman parte de las organizaciones, se sitúan tras los lienzos, usando sus cuerpos para afirmar las pancartas o banderas, más que para comunicar demandas.

Los lienzos colectivos soportados por los cuerpos homogéneos, por una parte, y los cuerpos heterogéneos como portadores de mensajes, por otra, constituyen los elementos característicos de las performances contestatarias de cada una de estas manifestaciones, reenviando hacia la emergencia de lo personal o de lo colectivo. Cada manifestación da cuenta de un despliegue performativo particular, así como una forma de expresar resistencia. Mientras que la predominancia del lienzo colectivo implica una subordinación de lo personal por lo político y una escisión entre uno y otro, la aparición de los cuerpos individuales implica una identificación de ambos, en tanto lo personal es político (Hanisch, 2016 [1969]). Los lienzos expresan de modo homogéneo y abstracto una lucha, mientras que el discurso expresado en el cuerpo mismo pone de manifiesto la imbricación de lo personal y diverso en la lucha, permitiendo la visibilización de sufrimientos cotidianos encarnados (hechos cuerpos) de las/os activistas que se sumergen en ella.

Estas formas performativas de manifestación dan cuenta de culturas de resistencia diferentes. En la manifestación del primero de mayo predominan las formas de expresión clásicas del movimiento social, que separan lo personal de lo político, aunque incluyan ciertas expresiones más contemporáneas como el carnaval callejero. Lo político es la demanda hecha consigna, la participación es mediada colectivamente y la reivindicación es institucionalizada. La manifestación del 8M, por su parte, da cuenta de una forma de interacción conflictiva con los sectores hegemónicos (García-Canclini, 1989). que se traduce en un despliegue de otras formas de comunicación. Allí se abre paso a expresividades vinculadas al carácter experiencial de la reivindicación, visibilizando un problema que trasciende la institucionalidad y apuntando a un cambio cultural en las propias formas de expresividad social. En este sentido, resulta novedoso observar que en esta performance el despliegue corporal transmite mensajes que no sólo reivindican, sino también transforman la experiencia dominante encarnando formas del cambio esperado en el propio cuerpo.

El análisis de performances da cuenta de modos de expresión contestataria en manifestaciones que sitúan al cuerpo en distintos lugares, como soporte o como medio de comunicación simbólica de contestación. A pesar de la amplitud conceptual de este enfoque, la ruptura que éste hace de la dualidad mente/cuerpo contribuye al desarrollo de una observación compleja del ámbito simbólico y representacional de las protestas. Éste permite ampliar el análisis de la acción contestataria más allá de los 
objetivos declarados por sus activistas, ya que nos invita a analizar el mensaje emitido por todos los elementos constitutivos de la acción performativa y no sólo por el lenguaje escrito u oral. El aporte de la etnografía para alcanzar dicho desafío es significativo. Basándose en la observación participante, incorpora los propios cuerpos de las/os investigadores/as en el trabajo de campo, haciéndolos parte de la experiencia del espacio social observado. Esto permite una descripción más acabada de la materialidad, las estéticas y los cuerpos activistas que encarnan y comunican contenido contestatario, multiplicando las posibilidades de análisis.

Profundizar y extender estas interpretaciones a otras manifestaciones, descentralizando las investigaciones hacia otras ciudades de Chile, como también a aquellas movilizaciones emergidas en la revuelta de octubre en el país, puede aportar en una comprensión más compleja de las múltiples dimensiones de las manifestaciones contemporáneas. Además, aplicar un enfoque de este tipo para el análisis de las protestas, y dentro de ellas a las dinámicas del enfrentamiento entre manifestantes y policías, altamente performativas y rituales, permitiría orientar la mirada hacia sus dimensiones culturales, en lugar de limitarse exclusivamente a la dimensión estratégica y dirigida a la política institucional. Para esto es útil también realizar una historización sobre los trabajos de performances y movimientos sociales en Chile y Latinoamérica, que permitan incorporar esta interpretación en un contexto socio-histórico más amplio. Estos elementos permitirán comprender más amplia y profundamente los procesos de resistencia como procesos complejos de comunicación simbólica que disputan no sólo con la política institucional, sino más ampliamente con la propia cultura dominante.

\section{Notas}

1. El término femenino "cuerpa" está siendo cada vez más usado, reivindicativamente, por colectivos y organizaciones feministas. Aquí omitimos su uso exclusivamente debido a la fluidez de la lectura.

2. El resguardo de la identidad de personas y agrupaciones es un elemento central de la ética antropológica, en general, y en estudios de movilización social, en particular, para resguardar la seguridad de las/os implicados. Por eso aquí sólo enunciamos nombres de agrupaciones en casos estrictamente necesarios, como marco general de los relatos. Nunca asociaremos nombres a acciones concretas.

3. Generalmente de barro o greda y con forma de útero, la copalera o nahuatl es donde se queman las hierbas, maderas y resinas para sahumar.

\section{Referencias}

Aguilera, Ó. (2012). Repertorios y ciclos de movilización juvenil en Chile (2000-2012). Utopía y Praxis Latinoamericana, 17(57), 101-108.

Aiziczon, F. (2018). Configuraciones militantes contemporáneas. Una propuesta metodológica para pensar el compromiso político. De Prácticas y Discursos, 7(9), 142-159.

Álvarez, R. (2014). La nueva política en el Chile postdictatorial: ¿Pasividad ciudadana o clientelismo desde abajo? (1990-1996). Estudos Ibero-Americanos, 40(1), 169-189.

Alexander, J. (2005). Pragmática cultural: un nuevo modelo de performance social. Revista Colombiana de Sociología, 24, 9-67.

Berger, M. \& Carrizo, C. (2016). La palabra del nos-otros. Reflexiones epistemológicas para la superación de las subalternidades en las luchas por derechos. Versión. Estudios de comunicación y política, 37, 129-139.

Bolados, P. \& Sánchez, A. (2017) Una ecología política feminista en construcción: En el caso de las "Mujeres en zonas de sacrificio en resistencia", Región de Valparaíso, Chile. Psicoperspectivas, 16(2), 33-42.

Boudreau, J., Boucher, N. \& Ligouri, M. (2009). Taking the bus daily and demonstrating on Sunday: Reflections on the formation of political subjectivity in an urban world. City, 13(2/3), 336-346. 
Chatterton, P., \& Pickerill, J. (2010). Everyday activism and transitions towards post-capitalist worlds. Transactions of the Institute for British Geographers, 35, 475-490.

Cherry, E. (2014). I was a teenage vegan: motivation and maintenance of lifestyle movements. Sociological Inquiry, 85(1), 55-74

Clifford, J. (2003 [1988]). “Sobre la autoridad etnográfica”. En Carlos Reynoso (ed.), El surgimiento de la antropología posmoderna (pp. 141-170). Barcelona: Gedisa.

Delgado, M. (2004). Del movimiento a la movilización Espacio, ritual y conflicto en contextos urbanos. Maguaré, 18, 125-160.

De Moor, J. (2017). Lifestyle politics and the concept of political participation. Acta Politica 52: 179-197. https://doi.org/10.1057/ap.2015.27

Escobar, A., \& Álvarez, S. (Eds.) (1992). The making of social movements in Latin America: identity, strategy and democracy. Boulder CO: Westview Press.

Fernandes-Jesus, M., Lima, M., \& Sabucedo, M. (2018). Changing Identities to Change the World: Identity Motives in Lifestyle Politics and Its Link to Collective Action. Political Psychology 39(5), 1031-1047.

Fischer-Lichte, E. (2011). Estética de lo performativo. Madrid: Abada Editores.

García-Canclini, N. (1989). Las culturas populares en el capitalismo. México: Nueva Imagen.

Garrido, J., \& Barrientos, C. (2018). Identidades en transición: Prensa, activismo y disidencia sexual en Chile, 1990-2010. Psicoperspectivas, 17(1), 17-27.

Geertz, C. (2003 [1973]). La interpretación de las culturas. Barcelona: Gedisa.

González, G. (2019). Escraches en redes feministas universitarias: una estrategia contra la violencia de género hacia las mujeres. Comunicación y Medios, 40, 170-182.

Guber, R. (2001). La etnografía. Método, campo y reflexividad. Bogotá: Grupo Editorial Norma.

Haenfler, R., B. Johnson, \& E. Jones. (2012). Lifestyle Movements: Exploring the Intersection of Lifestyle and Social Movements. Social Movement Studies: Journal of Social, Cultural and Political Protest, 11(1), 1-20.

Hall, S. \& Jefferson, T. (2003). Resistance through rituals. Youth subcultures in post-war Britain. Taylor \& Francis e-Library.

Hanish, C. (2016 [1969]). Lo personal es político. Ediciones Feministas Lúcidas. http://autonomiafeminista.cl/wp-content/uploads/2016/07/lo-personal-es-político_lucidas.pdf

Jirón, P., \& Imilan. W. (2016). Observando juntos en movimiento: posibilidades, desafíos o encrucijadas de una etnografía colectiva. Alteridades, 26(52), 51-64.

Juris, J. (2015). Embodying Protest: Culture and Performance within Social Movements. En: Anthropology, theatre, and development. The transformative potential of performance, (pp. 82-104). Flynn, A., \& Tinius, J. (eds). Hampshire: Palgrave Macmillan.

McCarthy, J., \& Zald, M. (1977). Resource Mobilization and Social Movements: A Partial Theory. The American Journal of Sociology, 82(6), 1212-1241.

Melucci, A. (1985). The Symbolic Challenge of Contemporary Movements. Social Research, 52(4), 789-816.

Nash, K. (2001). The cultural turn in social theory: towards a theory of cultural politics. Sociology, 35(1), 77-92.

Orellana, N. (2020). Repertorios y espacio público de trabajadores y estudiantes en Chile a comienzos del siglo XXI. Perfiles Latinoamericanos 28 (56), 99-124.

Osorio, S. \& Gaudichaud, F. (2018). ¿La democratización en contra de los trabajadores? La CUT, el movimiento sindical y el dilema de la transición pactada en Chile. Les Cahiers de Framespa, (27). https://doi.org/10.4000/framespa.4763. 
Portwood-Stacer, L. (2013). Lifestyle politics and radical activism. New York: Bloomsbury.

Prieto, A. (2002). Los estudios del performance: una propuesta de simulacro crítico. Cuadernos de investigación teatral, 1, 52-61.

Pudal, B. (2011). Enfoques teóricos y metodológicos de la militancia. Revista de Sociología, 25, 17-35.

Restrepo, E. (2018). Etnografía. Alcances, técnicas y éticas. Lima: Fondo Editorial de la Universidad Nacional Mayor de San Marcos.

Salazar, G. (2012). Movimientos sociales en Chile. Trayectoria histórica y proyección política. Santiago: Uqbar Editores.

Salinas, S. (2016). Conflictos y nuevos movimientos sociales. Santiago: RIL Editores.

Schechner, R. (2013 [2002]). Performance Studies: An Introduction. London: Routledge.

Sotirakopoulos N. (2016) The Rise of Lifestyle Activism. London: Palgrave Macmillan.

Tarrés, M. L. (1992). Perspectivas analíticas en la sociología de la acción colectiva. Estudios Sociológicos, $X(30), 735-757$.

Taylor, D. \& Fuentes, M. (2011). Estudios avanzados de performance. México D.F.: Fondo de Cultura Económica.

Tilly, C. (1978). From Mobilization to Revolution. New York: Random House-McGraw-Hill Publishing Co.

Tilly, C. (2005 [1995]). Popular contention in Great Britain, 1758-1834. Boulder, CO: Paradigm.

Touraine, A. (1978). La voix et le regarde. Paris: Seuil.

Velasco, H, \& Díaz de Rada, Á. (2006). La lógica de la investigación etnográfica. Madrid: Trotta.

Véron, 0. (2016). (Extra)Ordinary Activism: Veganism and the Shaping of Hemeratopias. International Journal of Sociology and Social Policy, 36(11/12), 756-773.

Yates, P. (2014). Everyday politics, social practices and movement networks: daily life in Barcelona's social centres. The British Journal of Sociology, 66(2), 236-258.

- Sobre los autores:

Nicolás Orellana Águila es investigador responsable Fondecyt Postdoctorado N03210149, Instituto de Asuntos Públicos, Universidad de Chile, Santiago, Chile. Es Doctor en Ciencias Políticas y Sociales por la Universidad Católica de Lovaina, Master en Sociología por la misma universidad y Licenciado en Antropología Social por la Universidad de Chile. Investigador responsable del proyecto FIIC 2018-02-01 (UAHC) del que este artículo es resultado.

Catalina Chamorro Ríos es Doctora en Sociología y Máster de Investigación en Sociología de la Universidad de Barcelona, Antropóloga Social de la Universidad de Chile. Co-investigadora del proyecto FIIC 2018-02-01 (UAHC) del que este artículo es resultado.

\section{- ¿Cómo citar?}

Orellana, N. \& Chamorro, C. (2021). El cuerpo y el lienzo. Las performances de las protestas feministas y laborales en Santiago. Comunicación y Medios, (43), 91-103.

https://doi.org/10.5354/0719-1529.2021.58478 